\title{
Fourier Transform Infrared Microspectroscopy Combined with Principal Component Analysis and Artificial Neural Networks for the Study of the Effect of $\beta$-Hydroxy- $\beta$-Methylbutyrate (HMB) Supplementation on Articular Cartilage
}

\author{
Izabela Świetlicka ${ }^{1, *(D)}$, Siemowit Muszyński ${ }^{1}$, Carina Prein ${ }^{2,3,4}$, Hauke Clausen-Schaumann 2,4®D, \\ Attila Aszodi $^{3}{ }^{\circledR}$, Marcin B. Arciszewski ${ }^{5}{ }^{\infty}$, Tomasz Blicharski ${ }^{6}{ }^{(}$, Mariusz Gagoś $^{7,8}$, Michał Świetlicki ${ }^{9}$, \\ Piotr Dobrowolski ${ }^{10}$, Katarzyna Kras ${ }^{5}$, Ewa Tomaszewska ${ }^{11}$ i] and Marta Arczewska ${ }^{1, *}$ (D)
}

\section{check for} updates

Citation: Świetlicka, I.; Muszyński, S.; Prein, C.; Clausen-Schaumann, H. Aszodi, A.; Arciszewski, M.B.; Blicharski, T.; Gagoś, M.; Świetlicki, M.; Dobrowolski, P.; et al. Fourier Transform Infrared Microspectroscopy Combined with Principal Component Analysis and Artificial Neural Networks for the Study of the Effect of $\beta$-Hydroxy$\beta$-Methylbutyrate (HMB) Supplementation on Articular Cartilage. Int. J. Mol. Sci. 2021, 22, 9189. https://doi.org/ 10.3390/ijms22179189

Academic Editor: Alfonso Baldi

Received: 26 July 2021

Accepted: 24 August 2021

Published: 25 August 2021

Publisher's Note: MDPI stays neutra with regard to jurisdictional claims in published maps and institutional affiliations.

Copyright: (c) 2021 by the authors. Licensee MDPI, Basel, Switzerland. This article is an open access article distributed under the terms and conditions of the Creative Commons Attribution (CC BY) license (https:// creativecommons.org/licenses/by/ $4.0 /)$
1 Department of Biophysics, Faculty of Environmental Biology, University of Life Sciences in Lublin, 20-950 Lublin, Poland; siemowit.muszynski@up.lublin.pl

2 Center for Applied Tissue Engineering and Regenerative Medicine-CANTER, Munich University of Applied Sciences, 80335 Munich, Germany; carina.prein@uwo.ca (C.P.); hauke.clausen-schaumann@hm.edu (H.C.-S.)

3 Laboratory of Cartilage Development, Diseases and Regeneration, Department for Orthopaedics and Trauma Surgery, Musculoskeletal University Centre Munich (MUM), University Hospital, LMU Munich, 82152 Planegg, Germany; attila.aszodi@med.uni-muenchen.de

4 Center for Nanoscience-CeNS, 80799 Munich, Germany

5 Department of Animal Anatomy and Histology, University of Life Sciences in Lublin, 20-950 Lublin, Poland; mb.arciszewski@wp.pl (M.B.A.); katarzyna.kras@up.lublin.pl (K.K.)

6 Chair and Department of Rehabilitation and Orthopedics, Medical University in Lublin, 20-090 Lublin, Poland; tomasz.blicharski@umlub.pl

7 Department of Cell Biology, Maria Curie Sklodowska University, 20-031 Lublin, Poland; mariusz.gagos@poczta.umcs.lublin.pl

8 Department of Biochemistry and Molecular Biology, Medical University of Lublin, 20-093 Lublin, Poland

9 Department of Applied Physics, Faculty of Mechanical Engineering, Lublin University of Technology, 20-618 Lublin, Poland; m.swietlicki@pollub.pl

10 Department of Functional Anatomy and Cytobiology, Faculty of Biology and Biotechnology, Maria Curie-Sklodowska University, 20-033 Lublin, Poland; piotr.dobrowolski@poczta.umcs.lublin.pl

11 Department of Animal Physiology, Faculty of Veterinary Medicine, University of Life Sciences in Lublin, 20-950 Lublin, Poland; ewaRST@interia.pl

* Correspondence: izabela.swietlicka@up.lublin.pl (I.Ś.); marta.arczewska@up.lublin.pl (M.A.) 
Keywords: FTIR microspectroscopy; atomic force microscopy; $\beta$-hydroxy- $\beta$-methylbutyrate supplementation; animal model; articular cartilage; collagen; proteoglycans; principal component analysis; artificial neural networks

\section{Introduction}

Articular cartilage (AC) is a non-vascular type of connective tissue covering the end of bones forming synovial joints to facilitate the distribution of loads across articular surfaces with a low frictional coefficient and buffer vibration [1]. The extracellular matrix (ECM) of AC is composed of a dense network of fibrillary collagen (primarily, type II collagen) that is associated with other non-collagenous proteins and proteoglycans (PGs) [2,3]. Structurally, the mature, non-calcified AC tissue demonstrates zonal heterogeneity due to the orientation of the collagen fibrils and molecular composition, thus it is subdivided into three histological zones (superficial zone (SZ), middle zone (MZ) and deep zone (DZ), of which the latter is separated from the calcified AC zone by the tidemark) [4]. In the relatively thin SZ with the lowest PGs content [5] but a high level of collagen, collagen fibrils are oriented in parallel to the AC surface. Such an arrangement is responsible for most of the tensile stiffness of cartilage. In the MZ (ca. 60\% of total AC thickness), collagen fibrils are mostly randomly organized, while in the DZ they are aligned perpendicular to the AC surface $[5,6]$. The specific structural framework of the collagen fibril network, their organization and the alterations in the content and spatial distribution of the main molecular components are responsible for the tensile biomechanical properties of $\mathrm{AC}[7,8]$. The concentration of PGs is unevenly distributed throughout the tissue depth and reaches its maximum in the DZ. Among the PG family, largely aggregating aggrecan is considered the most crucial to the proper functioning of AC. It contains covalently attached side chains of the glycosaminoglycans (GAGs), chondroitin sulphate (CS) and keratin sulphate (KS) linked to a protein core. The CS chains of aggrecan play a major role in absorbing free ions and water into cartilaginous tissues, which provides the basis of its hydrodynamic viscoelastic properties as a weight-bearing tissue [9]. In this way, PGs are mainly responsible for the resiliency and compressive properties of AC. Unfortunately, AC, if damaged, displays a limited ability to self-regenerate $[10,11]$. Therefore, there is an ongoing intensive search for novel therapies, including preventive interventions and therapeutic solutions that can stimulate tissue regeneration and reduce cartilage degeneration.

HMB ( $\beta$-hydroxy- $\beta$-methylbutyrate) is a natural, bioactive metabolite of the essential amino acid leucine. It has recently gained popularity as a dietary supplement due to its many beneficial effects on the skeletal system of animals via protective, anti-catabolic mechanisms and a direct influence on protein synthesis [12-14]. HMB has been shown to reduce protein breakdown by decreasing proteasome expression and proteasome enzyme activity, inhibit caspase up-regulation and limit apoptosis of muscle nuclei $[15,16]$. Moreover, Santos-Fandila et al. [17] reported in the brain microdialysis experiment that after being orally administered, HMB is able to cross the blood-brain barrier, which opens up new ways for its nutritional interventions, particularly concerning anti-ageing cognitive benefits. Regarding AC tissue, several studies have shown that the supplementation of HMB affects the distribution and structure of cartilage components [18-21]. The more significant changes after prenatal and maternal HMB-treatment of animals were seen in enhancing proteoglycan content and an intensive process of collagen synthesis.

The fundamental parameters such as collagen content, its integrity, the orientation of collagen fibers and PGs content provide information about the AC quality [3]. However, the spatial distribution of collagen and PGs is hardly measurable with conventional biochemical methods. To address this problem, techniques that can visualize the spatial distribution of $\mathrm{AC}$ molecular components are required. Fourier transform infrared microspectroscopy, being a powerful technique, can quantitatively evaluate the distribution of chemical composition of biological tissues. It gives the possibility of simultaneously 
achieving the collection of infrared spectra and spectral maps based on the absorbance of a specific molecular species with satisfactory spatial and spectral resolutions [22]. So far, FTIR spectroscopy and its combination with microscopic visualization of the AC tissue have been successfully applied both to evaluate the relative changes in its composition and the spatial distribution of main AC components [23-26]. The development of FTIR spectroscopy in the $\mathrm{AC}$ research to provide a new strategy for rapid diagnosis of degenerative disease was reported elsewhere [27-30] and demonstrated by the changes in the spatial distribution of various components of AC mapped by FTIR microspectroscopy [31]. Using advanced multivariate data analysis methods, FTIR microspectroscopy can reveal hidden structures within spectral data concerning the tissue composition and structure, thereby helping improve medical diagnostics of cartilage diseases or monitor therapeutic progress [31]. Yin et al. [32] applied FTIR imaging to examine the collagen and PG levels and their depth dependence on healthy and osteoarthritis-affected cartilages. This technique has also been used to assess chemical changes associated with load, disuse, degradation and repair in cartilage and micro-damage in bone $[33,34]$.

The present study aimed to involve multiple techniques, including FTIR microspectroscopy and atomic force microscopy (AFM), and combine them with multivariate methods such as principal component analysis (PCA) and artificial neural networks (ANNs) to reveal the variations in the structure and properties of cartilage tissue. We developed a swine model to investigate in vivo the influence of HMB supplementation during the fetal period on articular cartilage. The pig provides an attractive model to human health research priorities and nutritional studies because of many similarities to humans in structure and function, including the size of internal organs, feeding patterns, drug metabolism and dietary habits [35]. There is a general acceptance of the pig as a biomedical model after sequencing the complete swine genome and finding a high sequence homology to humans (ca. 60\%) [35,36]. To our knowledge, there is no investigation regarding the HMB-related spatial distribution of collagen and proteoglycans in the extracellular matrix of cartilage tissue utilizing FTIR imaging and methods of multivariate data analysis.

\section{Results and Discussion}

Articular cartilage is recognized as a tissue with structure, composition and functional properties that relevantly change during skeletal maturation. Observed alterations include but are not limited to increasing collagen network density, reorganization of chondrocytes and decrease in cellularity [37]. $\beta$-hydroxy $\beta$-methylbutyrate, administered during the prenatal period, was proved to enhance the mechanical, morphological and physiological features of tissues of offspring [20,38-42]. Since the mechanism of HMB action remains unknown, it is hypothesized that HMB could affect protein metabolism acting on several levels, e.g., inhibiting proteolysis, attenuating depression in protein synthesis, metabolic inhibitors and promoting protein synthesis [43-46], which is manifested by modifications in skeletal muscle structure as well as by changes in the mechanical and morphological properties of bone $[18,20,40,42,47]$ and teeth [41]. Therefore, the first step of our research was to apply FTIR microspectroscopy to map the changes in the spatial distribution of AC components.

Figure 1A shows the average infrared absorption spectra collected from the superficial, middle and deep zones of cartilage, corresponding to the areas shown in Figure 2A. The characteristic bands of collagen and PGs cover the range of $1800-960 \mathrm{~cm}^{-1}$, including the amide I (1700-1600 $\left.\mathrm{cm}^{-1}\right)$, the amide II $\left(1600-1500 \mathrm{~cm}^{-1}\right)$, the amide III $\left(1300-1200 \mathrm{~cm}^{-1}\right)$ and the $\mathrm{C}-\mathrm{O}$ stretching vibrations of the carbohydrate residues in collagens and PGs (1140-960 $\mathrm{cm}^{-1}$ ) [48]. The bands located between the spectral range of $1500-1300 \mathrm{~cm}^{-1}$ are mixed and relate to $\mathrm{CH}_{2}$ and $\mathrm{CH}_{3}$ vibrations and $\mathrm{CH}_{2}$ side chains vibrations of collagen [32,33]. More importantly, the bands located at $1338 \mathrm{~cm}^{-1}$ and in the region of $1080-1060 \mathrm{~cm}^{-1}$ are the most suitable for distinguishing collagen and PGs [49]. Since the absorption bands in the spectra of biological samples often overlap each other and the bands originating from collagen and other molecules of AC, such as chondroitin sul- 
phate, are located in the same region, the second derivative method has been applied to enhance resolution in identifying subbands and better evaluate the spectral changes [50,51]. Rieppo et al. [29] reported a practical approach based on a second derivative analysis of collagen and PGs for the analysis of articular cartilage composition. The most significant peaks obtained from the second derivative spectra are shown in Figure 1B, while the assignments of the minima found in the 2 nd derivative spectra are presented in Table 1.
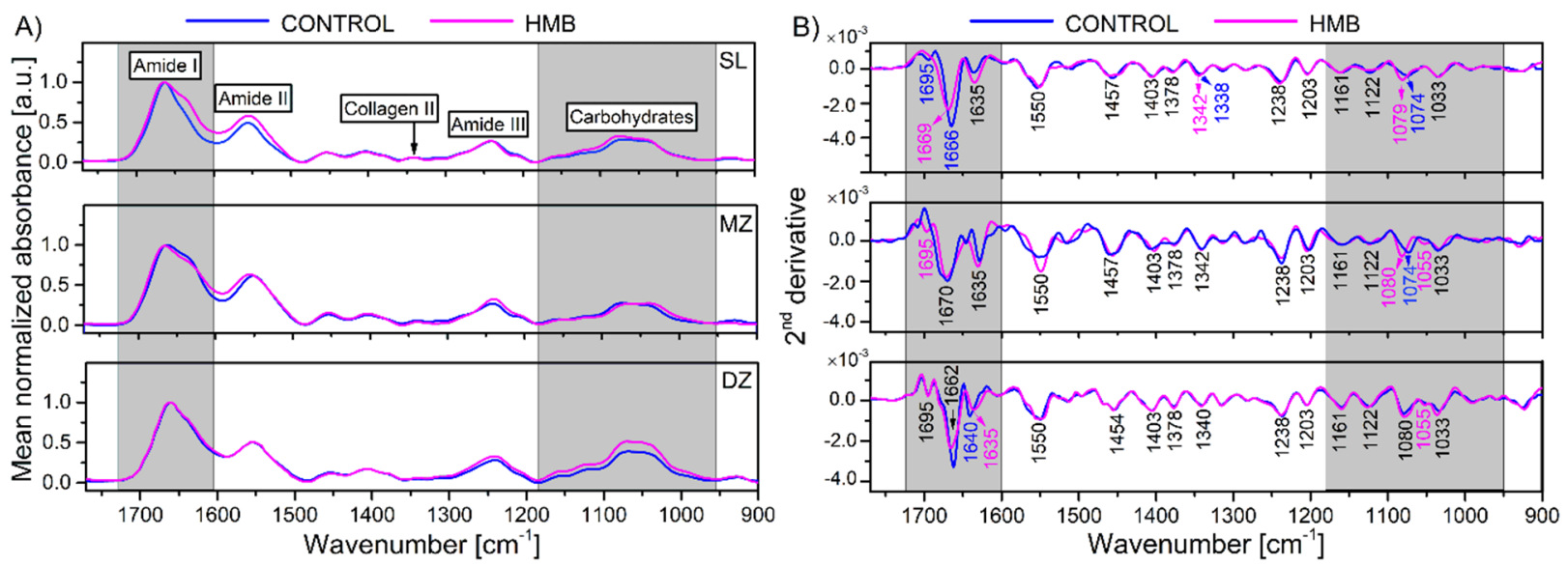

Figure 1. (A) Mean ( $n=75$ spectra) FTIR spectra of the cartilage matrix from control (blue line) and HMB-treated pigs (magenta line) in three regions after background correction and normalization based on the amide I band intensity, and (B) mean second-derivative spectra from the same samples calculated using the Savitzky-Golay algorithm with nine smoothing points. The second-derivative band assignments were given in Table 1 . The band positions in black indicate the same values for all samples. HMB—supplemented group, SZ—superficial zone, MZ—middle zone, DZ—deep zone.

Significant differences in the mean second-derivative spectra were found in the amide I band of the collagen helix and at the carbohydrates regions commonly used to estimate collagen and proteoglycan contents. The bands localized at $1695 \mathrm{~cm}^{-1}, 1635 \mathrm{~cm}^{-1}$ and about $1660 \mathrm{~cm}^{-1}$ were assigned as characteristics for $\beta$-sheet and $\alpha$-helix structures of amide I. The increase in the band intensity at $1635 \mathrm{~cm}^{-1}$ may indicate the presence of proteins with a more $\beta$-sheet structure for the HMB-supplemented samples in the SZ compared to the control. Moreover, a more prominent intensity of this band was observed in collagen-rich tissues due to the cross-linked collagen fibers [52]. In the mouse model, the presence of a $1635 \mathrm{~cm}^{-1}$ band indicated proteoglycan synthesis by surface activated chondrocytes [53]. Hence, the more reliable explanation of these alterations could cover newly synthesized collagen produced by activated chondrocytes or other unknown cartilage proteins observed in the HMB-supplemented samples, especially in the superficial zone. The obtained results are consistent with our previous work, in which significantly changed collagen structure in the articular cartilage of maternal HMB-supplemented newborn piglets was reported [18]. On the other hand, a higher relative contribution of extended $\beta$-sheets was observed in the dried tissue matrix [54]. It is worth mentioning that some limitations due to air drying of AC samples before FTIR analysis should be taken into account, especially in evaluating the amide I band. Water plays an essential role in maintaining the extracellular matrix, and dehydration may cause some changes in the structural organization of molecular components constituting articular cartilage, mainly collagen [55]. Kemp et al. reported that collagen fibril D-spacing decreases with dehydration, contributing to compromised mechanical integrity [56]. In the FTIR analysis of fully hydrated tissues, the absorbance band from water's bending vibration near $1640 \mathrm{~cm}^{-1}$ overlaps seriously with the amide I band; therefore, tissue samples are generally dehydrated before analyses $[31,48,57,58]$. 
A)

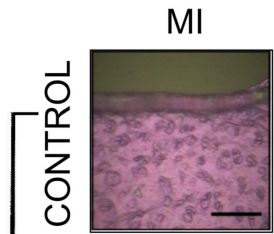

SZ
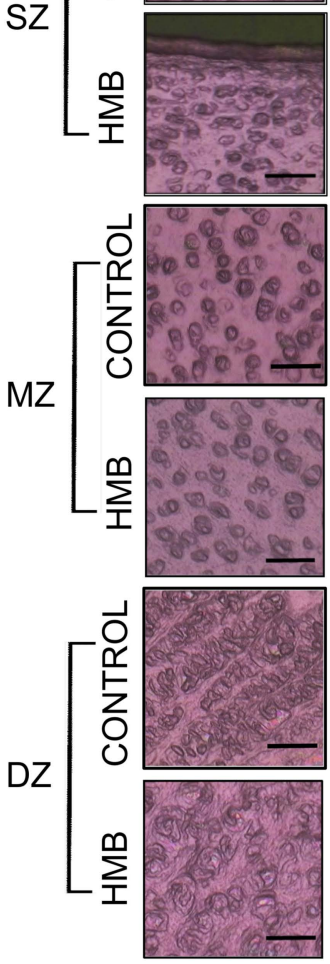

CC
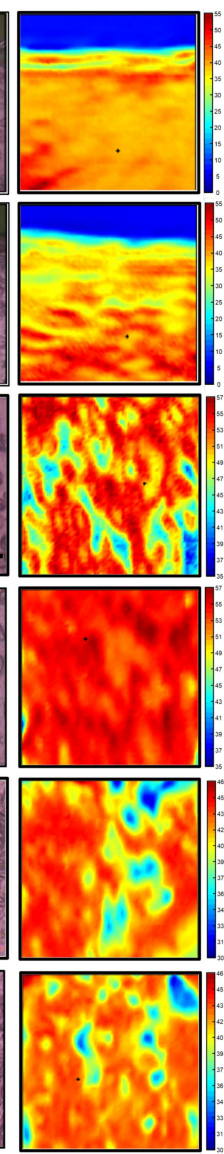
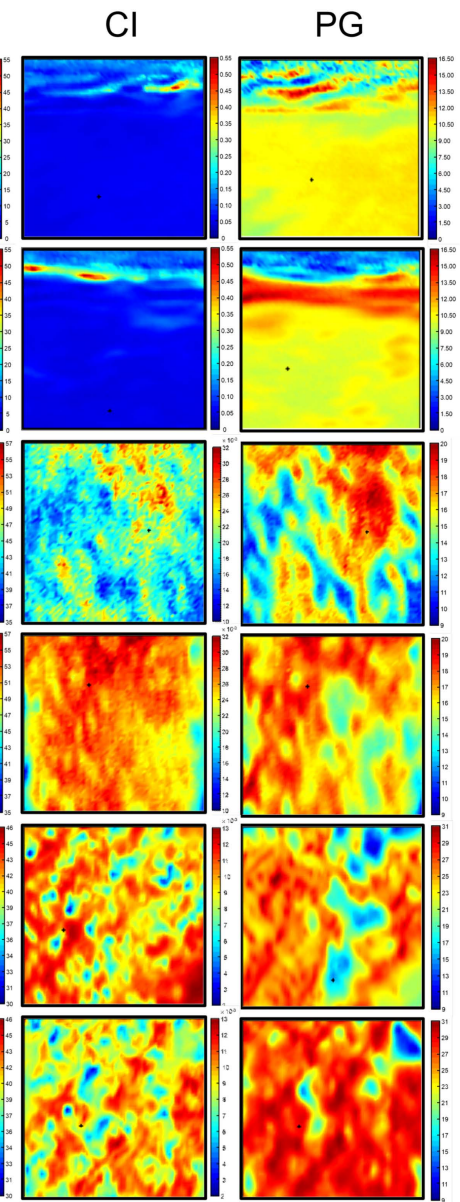
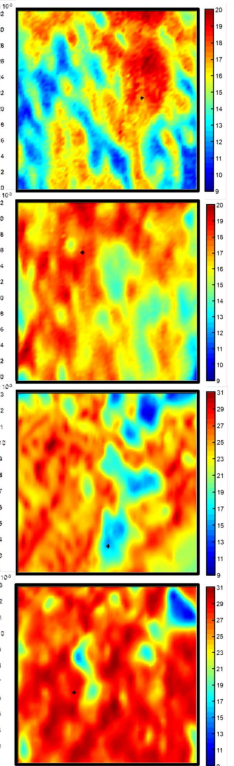

B)
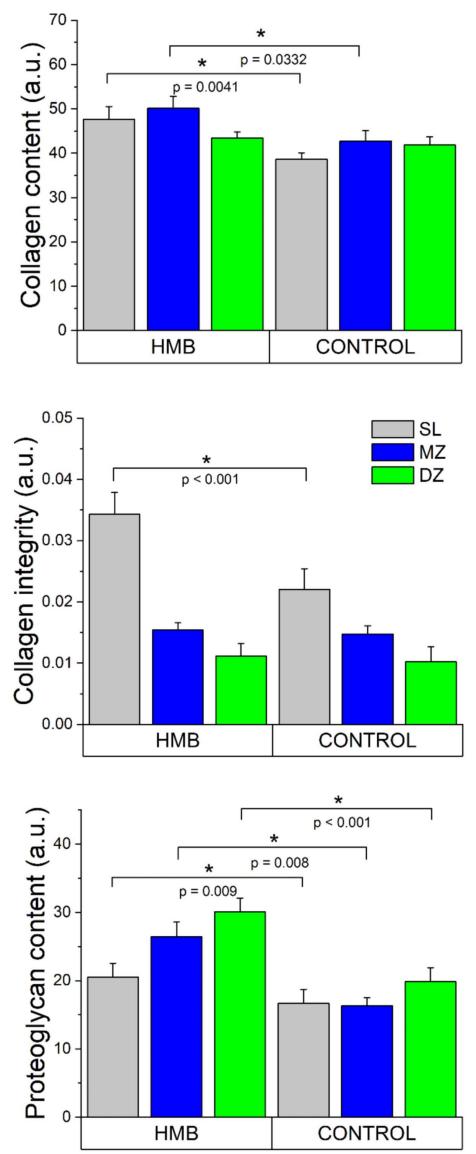

Figure 2. (A) The visible light microscopic images (MI) and representative chemical maps of porcine cartilage in three histological zones: superficial zone (SZ), middle zone (MZ) and deep zone (DZ), along with (B) the histograms of structural parameters characterizing articular cartilage: collagen content, collagen integrity and proteoglycans content with statistically significant differences between groups (at $p<0.05$ ) marked with *. Chemical maps were constructed by integrating the area under the amide I band 1700-1600 cm $\mathrm{cm}^{-1}$ (CC) as the ratio of the area of the $\mathrm{CH}_{2}$ side chain of collagen $1360-1325 \mathrm{~cm}^{-1}$ absorption to the amide II 1590-1490 $\mathrm{cm}^{-1}$ (CI) and by integrating the area of the region assigned to the proteoglycans sugar ring 1140-965 cm $\mathrm{cm}^{-1}$ (PG) in control and HMB-treated samples. The color scale indicates the pixel values for all parameters. These maps were typical of all samples. The scale bars correspond to $20 \mu \mathrm{m}$. HMB—supplemented group, SZ—superficial zone, MZ—middle zone, DZ—deep zone, CC—collagen content, CI—collagen integrity, PG—proteoglycans content.

No significant differences in band locations were found in the region between $1500 \mathrm{~cm}^{-1}$ and $1200 \mathrm{~cm}^{-1}$, except for the spectral shift $\left(\sim 4 \mathrm{~cm}^{-1}\right)$ of a band at $1338 \mathrm{~cm}^{-1}$ assigned to the $\mathrm{CH}_{2}$ side-chain vibrations in the case of $\mathrm{HMB}$-supplemented samples. This band is commonly used to qualitatively estimate the integrity of the collagen network because it is not present in the pure PG spectrum [49,57]. The absorption intensity of the PG-related second derivative bands increased, especially for the DZ zone. In addition, a band at $1074 \mathrm{~cm}^{-1}$ showed the variability with the larger spectral shift towards higher wavenumbers in the HMB supplemented groups compared to the control. Interestingly, a band at $1055 \mathrm{~cm}^{-1}$ presented only in the DZ zone of the control group, while in the case of HMB-supplemented samples, it was observed in low depth regions of cartilage.

As shown in Figure 2A, chemical maps present cartilage samples as distributions of functional groups characteristic of the selected components of cartilage, namely collagen and proteoglycans. Chemical maps converted into quantities proportional to the integrated area of the chosen bands were used to characterize its structural parameters quantitatively. Mean values of collagen content (CC), collagen integrity (CI) and proteoglycans content 
(PG) were compared between the control and HMB groups in each zone (complete data available in the Supplementary Material, Figures S1-S3).

Table 1. The most significant bands obtained from the second derivative FTIR spectra. An assignment of spectral features was collected according to the literature $[23,25,26,29,57,59]$.

\begin{tabular}{|c|c|}
\hline Wavenumber $\left[\mathrm{cm}^{-1}\right]$ & Assignment of Second Derivative FTIR Bands of AC \\
\hline $1695, \sim 1660,1635$ & $80 \% \vee(\mathrm{C}=\mathrm{O}), 20 \% \vee(\mathrm{CN}), \tau(\mathrm{HOH})$, amide I from PGs, water \\
\hline 1550 & $60 \% \tau(\mathrm{N}-\mathrm{H}), 30 \% \vee(\mathrm{C}-\mathrm{N}), 10 \% v(\mathrm{C}-\mathrm{C})$, amide II \\
\hline 1457 & $\delta_{\mathrm{as}}\left(\mathrm{CH}_{3}\right)$ \\
\hline 1403 & $v_{\mathrm{s}}\left(\mathrm{COO}^{-}\right)$of GAGs \\
\hline 1378 & $\delta_{\mathrm{s}}\left(\mathrm{CH}_{3}\right)$ of GAGs \\
\hline$\sim 1340$ & $\mathrm{CH}_{2}$ side-chain vibrations of collagen II \\
\hline 1238 & $v_{\mathrm{as}} \mathrm{SO}_{3}{ }^{-}$of sulphated GAGs with $\mathrm{CH}_{2}$ wagging vibration from the glycine backbone and proline side-chain \\
\hline 1204 & $v(\mathrm{C}-\mathrm{N})$ of amide III, $\delta(\mathrm{N}-\mathrm{H})$ of collagen \\
\hline 1161 & $v(\mathrm{C}-\mathrm{O})$ of the carbohydrate residues \\
\hline 1122 & $v_{\mathrm{as}}(\mathrm{C}-\mathrm{O}-\mathrm{S})$ \\
\hline $1080-1060$ & $\begin{array}{c}v(\mathrm{C}-\mathrm{O}) \text { of the carbohydrate residues in PGs, } \\
v_{\mathrm{S}} \mathrm{SO}_{3}-\text { of sulphated GAGs }\end{array}$ \\
\hline$\sim 1050$ & $v(\mathrm{C}-\mathrm{O})$ of the carbohydrate residues in collagen and PGs \\
\hline 1033 & $v(\mathrm{C}-\mathrm{O})$ of the carbohydrate residues in collagen and PGs \\
\hline
\end{tabular}

The symbols concerning the vibrations assignment are related to the vibrational stretching mode $(v)$, deformational $(\delta)$, bending $(\tau)$, and symmetrical (s) and asymmetrical (as) modes.

Obtained results show (Figure 2B) that in the group supplemented with HMB during the prenatal period, the collagen content increased in the $\mathrm{SZ}$ by more than $23 \%$ and in the $\mathrm{MZ}$ by about $17 \%$, while no changes in the deep zone compared to the control group were observed. In the experimental group, a significant (approximately 55\%) increase in the integrity of collagen in the surface zone were also detected. Interestingly, all three zones proved to be influenced by HMB administration when proteoglycans content was considered. A significant increase was observed in all of the examined areas; however, the highest ones were registered in the middle (62\% compared to the control) and deep (52\% compared to the control) zones. Achieved results are in line with histological proteoglycan staining (Supplementary Material, Figure S4).

It is proven that any modification in tissue organization is reflected in changes in mechanical features such as elasticity, stiffness and others [37]. Furthermore, mechanical properties measured in the nanoscale are recognized to be highly correlated with the structure of biological materials determined with spectral methods [60]. To examine whether structural alterations influenced tissue elasticity, AFM nanoindentation measurements were carried out.

Conducted AFM analysis revealed differences in the mechanical properties of articular cartilage collected from animals administered with HMB during the prenatal period when compared to the control. A shift towards higher values of Young's modulus was detected for all the zones (Figure 3, Table 2), with the greatest being observed for the superficial and middle zones. According to our previous work [19], where the higher presence of collagen fibers (indicating higher collagen maturity), increased AC thickness and PGs content in offspring were also observed, prenatal HMB supplementation upregulated leptin indirectly by enhancing the growth hormone IGF-1 and the pituitary-gonadal axis, which led to cell proliferation and more advanced collagen maturation. Those findings may explain the observed increase in tissue stiffness, which, among others, depends on both collagen content and the distribution of the chondrocytes within the tissue [61-64]. 

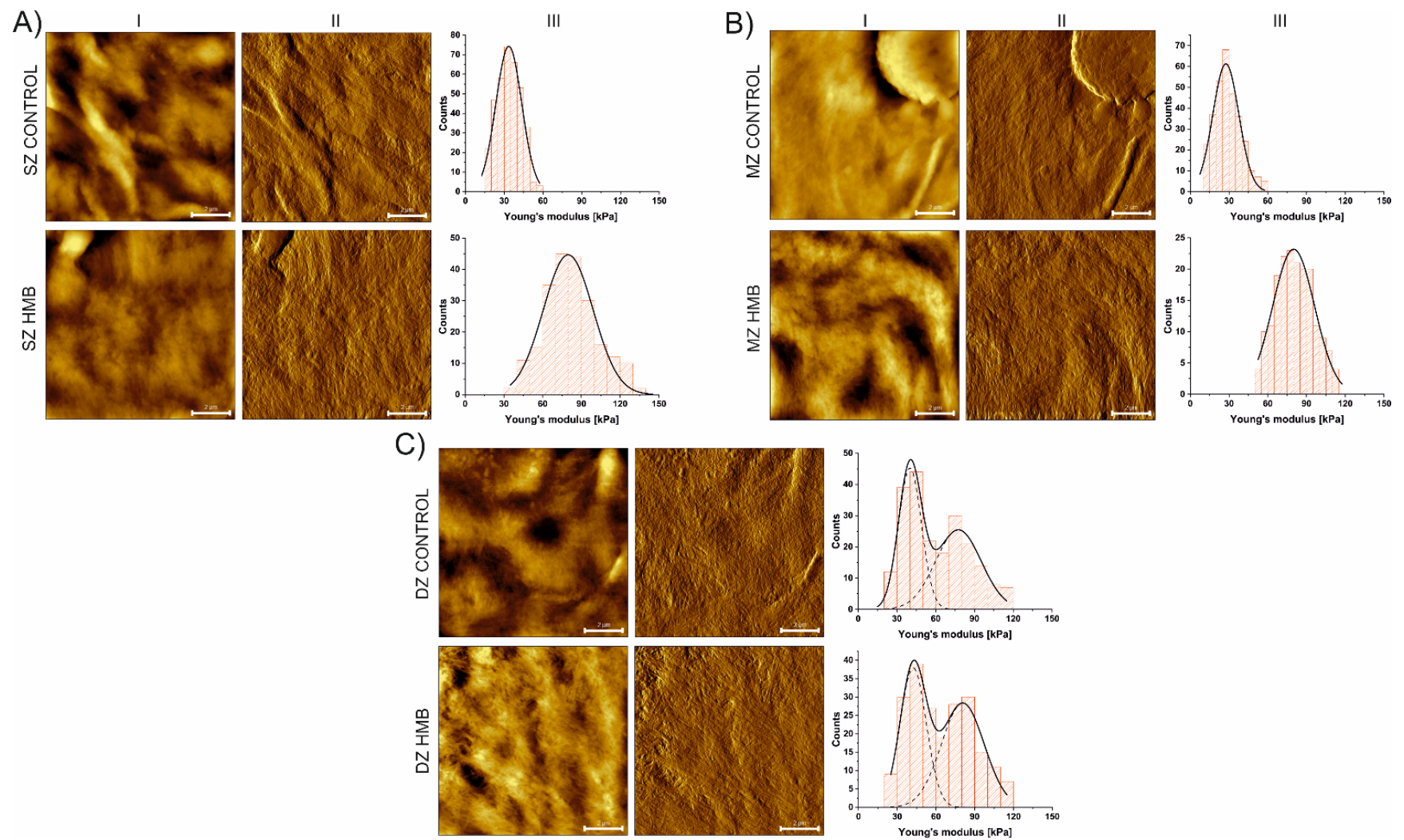

Figure 3. Height (I) and vertical deflection (II) images of AC zones with corresponding histograms of Young's modulus distribution (III) determined for SZ (panel A), MZ (panel B) and DZ (panel C) with Gaussian functions fitted. Scale bars are equal to $2 \mu \mathrm{m}$. HMB—supplemented group, SZ—superficial zone, MZ—middle zone, DZ—deep zone.

Table 2. Values of Young's modulus given as means \pm SD. Statistically significant differences between groups (at $p<0.05$ ) were signed by ${ }^{\mathrm{a}}, \mathrm{b}, \mathrm{c}$ and ${ }^{\mathrm{d}}$.

\begin{tabular}{|c|c|c|c|}
\hline Group & \multicolumn{2}{|c|}{ Zone } & $\begin{array}{c}\text { Young's Modulus } \\
{[\mathrm{kPa}]}\end{array}$ \\
\hline Control & \multicolumn{2}{|c|}{ SZ } & $33.88( \pm 0.58)^{a}$ \\
\hline HMB & \multicolumn{2}{|c|}{ SZ } & $88.82( \pm 1.18)^{b}$ \\
\hline Control & \multicolumn{2}{|c|}{$\mathrm{MZ}$} & $29.16( \pm 0.67)^{\mathrm{a}}$ \\
\hline HMB & \multicolumn{2}{|c|}{$\mathrm{MZ}$} & $80.02( \pm 0.74)^{b}$ \\
\hline \multirow{2}{*}{ Control } & \multirow[b]{2}{*}{ DZ } & 1st peak & $40.02( \pm 1.03)^{a}$ \\
\hline & & 2nd peak & $77.58( \pm 0.79)^{b}$ \\
\hline \multirow{2}{*}{ HMB } & \multirow{2}{*}{ DZ } & 1st peak & $42.72( \pm 1.51)^{\mathrm{c}}$ \\
\hline & & 2nd peak & $81.38( \pm 1.19)^{d}$ \\
\hline
\end{tabular}

HMB-supplemented group, SZ-superficial zone, MZ-middle zone, DZ-deep zone, CC—collagen content, $\mathrm{CI}$-collagen integrity, PG-proteoglycans content. The first peak in a bimodal distribution of Young's modulus in the DZ is connected with the proteoglycan phase, while the second peak is attributed to the collagen phase [61,65].

On the other hand, the chemical composition of AC could change during cartilage growth and maturation as a result of different joint loadings [25]. In our experiment, the HMB-supplemented male piglets had a higher body weight at weaning compared to the control groups (Table S1 in the Supplementary Materials). This feature could also be associated with higher joint loading or an adaptation to the amount of mechanical loading. Saadat et al. have reported an increase in PG content in a rabbit model due to physiologic in vivo cyclical joint loading localized in the DZ only, with unchanged collagen content [66]. This finding indicates a healthy joint response in which chondrocytes detect and react to the changes in their mechanical environment by activating proteoglycan biosynthesis. 
However, being useful in the examination of biological samples, FTIR spectroscopic imaging has several limitations, including long image acquisition times and a vast amount of data received as a result of the analysis. Moreover, spectral analysis in some regions of FTIR spectra is complicated as features characteristic for lipids, proteins or carbohydrates often overlap each other $[26,29,67]$. In addition, spectroscopic data also contains plenty of unused information due to difficulty in identifying beneficial features. Therefore, additional analysis tools are needed to determine the differences in the distribution of cartilage chemical components after HMB supplementation. In view of these difficulties, principal component analysis (PCA) and artificial neural networks (ANNs) were applied.

The principal component analysis is one of the most popular methods applied in the feature extraction process [68]. The PCA algorithm creates new features, lower in dimension, that project the original feature vectors into a new space. This reduction is achieved by a linear transformation to a new set of variables, which are uncorrelated and are ordered according to their importance in representing the original variables [68]. By numerous applications in engineering and biology [69-71], PCA proved to be useful and effective. In our present study, PCA supports resolving overlapping spectral features and provides further information about the main spectroscopic features and their variation for the set of AC samples. The results of spectral studies using PCA are shown in Figure 4A. The score plot displays several independent or overlapping clusters, using the two first components based on 75 spectra of the different AC samples. Figure $4 \mathrm{~A}$ revealed distinct clustering of the control and HMB-supplemented groups in the SZ and DZ. There was a clear separation between the control and HMB groups in the SZ zone, with the DZ region overlapping with the control DZ and SZ. The DZ in the HMB-treated group was the most decentralized from other areas of the same AC sample. On the other hand, the PCA scores showed less separation between the control MZ and the SZ from the HMB-supplemented group.

A)

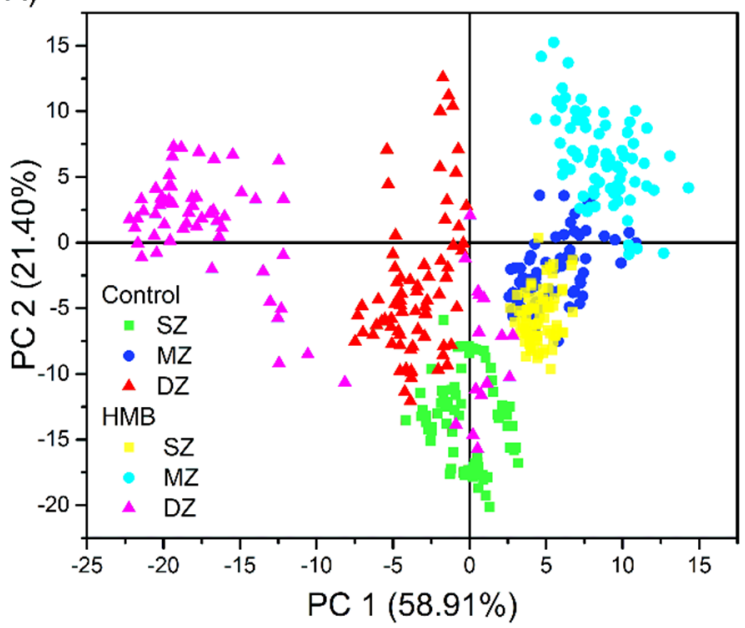

B)

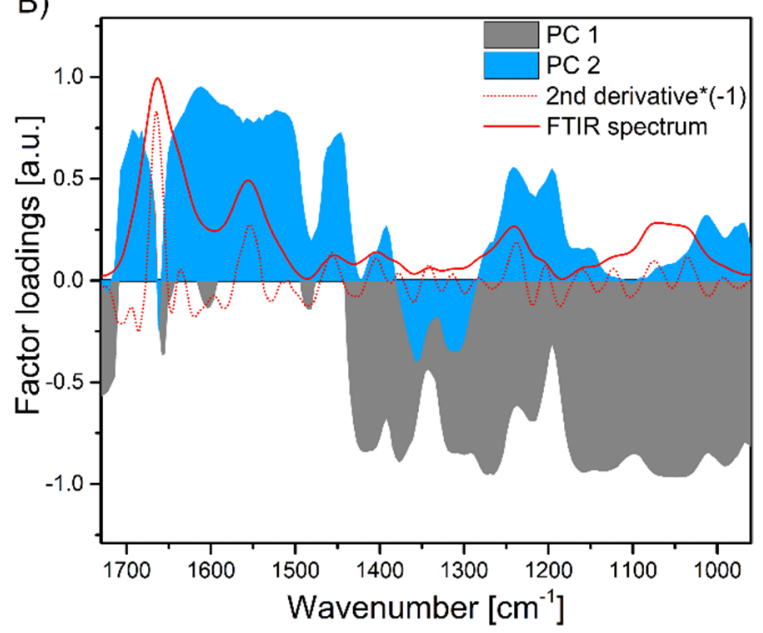

Figure 4. PCA score (A) and factor loading (B) plots of the first and the second principal components based on the infrared spectra of articular cartilages (AC) samples from the control and HMB-supplemented group in the region of $1730-960 \mathrm{~cm}^{-1}$. In (B), a solid red line corresponding to a typical FTIR spectrum and a dotted line to its second derivative (multiplied by -1 ) revealed the mid-infrared regions covered by factor loadings. HMB-supplemented group, SZ-superficial zone, MZ-middle zone, DZ-deep zone.

When the loading plots are observed (Figure 4B), the shape and position of PC 1 and PC 2 factor loadings are similar to a typical FTIR spectrum and its second derivative from the AC sample. Therefore, the first two components, PC 1 and PC 2, which can be easily interpreted concerning the biochemical components of the AC tissue, were considered for further discussion. The cumulative contribution of variance for the first two PCs was $80.31 \%$, implicating that most of the information contained in the spectral matrix 
has been retained (Figure 4A). The PC 1 explains $58.91 \%$ of the total variance, and it is characterized by significant negative loadings (absolute value of the loading $>0.7$ ) of the aliphatic absorption bands $\left(\mathrm{CH}_{3}, \mathrm{CH}_{2}\right.$, Table 1$)$, the amide III and the PG-related bands. The PC 2 explains $21.40 \%$ of the total variance. Predominantly, the amide I and II absorption bands display large positive loadings (Figure 4B). Moreover, positive loadings at the amide III absorption region separated control from HMB-supplemented samples. The amide I and amide II regions are affected by the $\mathrm{C}=\mathrm{O}, \mathrm{C}-\mathrm{N}$ and $\mathrm{N}-\mathrm{H}$ vibrations characterized by collagen and PGs. Nevertheless, since approximately $60 \%-80 \%$ of the solid cartilage matrix is composed of collagen and PGs make the rest, the collagen molecules mainly dominate this region [72].

Since the PCA method is based on the linear relationships between variables, it was decided to apply an algorithm operating on nonlinear data processing, such as ANNs. Artificial neural networks are considered an excellent tool in classification and recognition problems. Unlike classical linear modelling, they facilitate solving complex nonlinear problems and simplify difficult multidimensional spaces by presenting the issue in the form of small-dimensional geometric relationships [73]. Moreover, ANNs can learn and are able to generalize, have fault tolerance and the possibility of parallel data processing [73,74]. In the presented research, two different ANNs were used: the multilayer perceptron network (MPL) and the Kohonen network. MLP is known for its outstanding results in classification problems mainly due to the fact that in the learning process, the activation level of the output neuron is transferred to the value of the output variable [74]. At the same time, the Kohonen network has two basic properties that distinguish it from other networks and make it a helpful tool for pattern detection: it is able to represent a multivariate input vector as a one- or two-dimensional output vector and can detect groups [75].

As presented in Table 3,100\% of the cases taking part in the MLP's training and testing and $99 \%$ of the validation set were assigned correctly to the group. Furthermore, the activation levels of the output neurons ranged from 0.97 to 1.00 (Supplementary Material, Figure S5), which indicates that the network was entirely certain about the affiliation of analyzed cases to the given class.

Table 3. Results of the MLP network training process.

\begin{tabular}{ccccccc}
\hline \multirow{2}{*}{ Network } & \multicolumn{3}{c}{ Recognition Rate } & \multicolumn{2}{c}{ Function } \\
\cline { 2 - 7 } & Training & Validation & Testing & Error & Activation (Hidden) & Activation (Output) \\
\hline MLP & 1.00 & 0.99 & 1.00 & Entropy & Logistic & Softmax \\
\hline
\end{tabular}

Only one case from the validation set, which was derived from the HMB-supplemented DZ group, was assigned incorrectly to the control DZ group (confusion matrix available in the Supplementary Material, Table S2). Gain charts (Figure 5) constructed for examined groups show that by taking the top $20 \%$ (shown on the $x$-axis) of the cases classified into the corresponding category with the greatest certainty (maximum classification probability), we will correctly classify nearly $80 \%$ of all cases.

As a result of the training process (Table 4), clustering the SOM network with 25 neurons in the output zone divided the presented dataset into six groups (Figure 6). As can be seen, neurons winning in the training created clusters based on the similarity of given vectors describing the examined groups: control (SZ, MZ and DZ) and HMB (SZ, $\mathrm{MZ}$ and DZ). It might be observed that neurons winning for the middle zone and deep zone in the HMB group are located in the opposite corners of the square-shaped network, indicating that SOM considered them completely different. Similar behavior may be seen for the deep zone from the control group and the superficial zone from the HMB group. By contrast, groups such as the middle zone in the control and HMB groups are similar to a greater extent, so they are located close to each other on the SOM map. 
A)

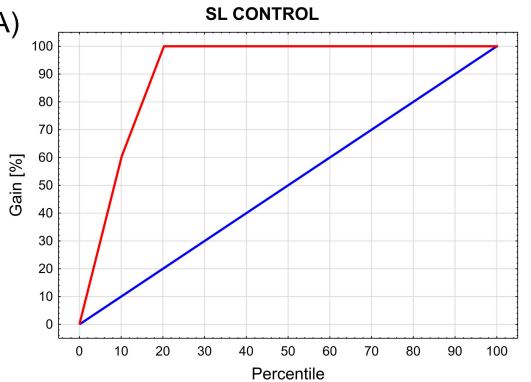

SL HMB

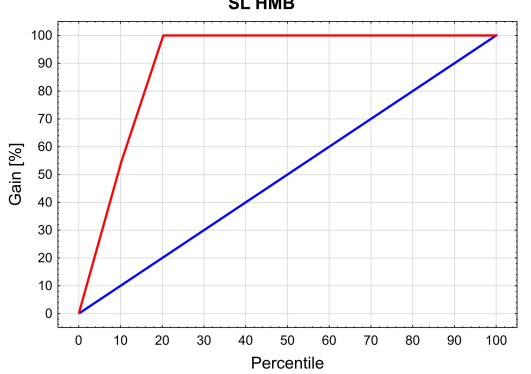

B)

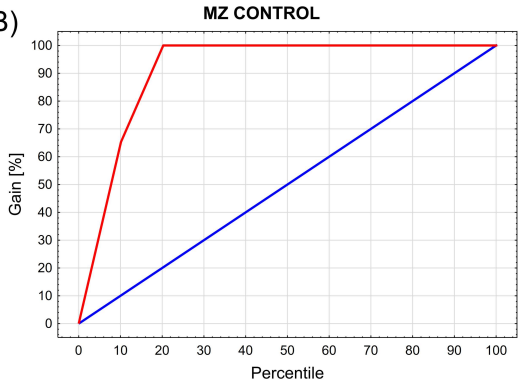

MZ HMB

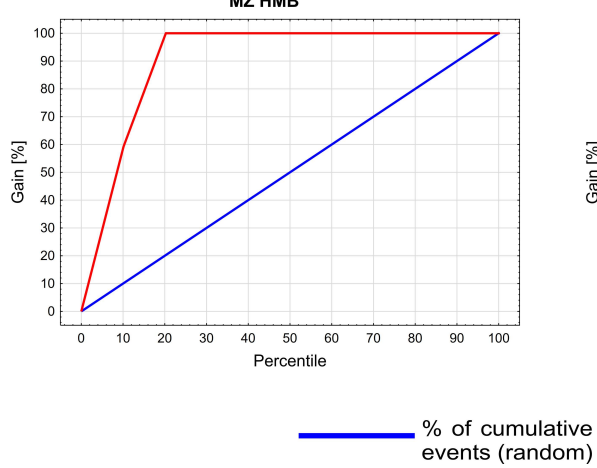

C)

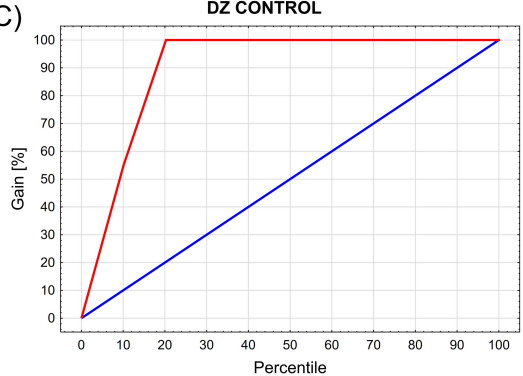

DZ HMB

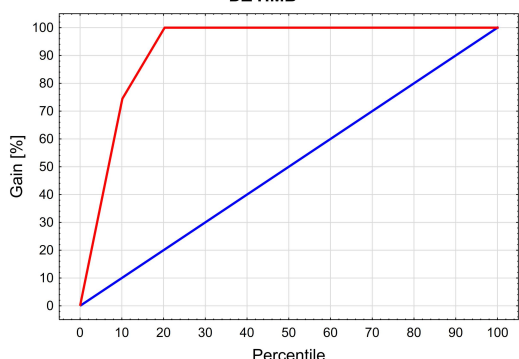

$\%$ of cumulative
events (model)

Figure 5. Gain charts constructed for the examined groups showing the effectiveness of a classification model calculated as the ratio between the results obtained with (red line) and without (blue line) the model. HMB-supplemented group, SZ—superficial zone, MZ—middle zone, DZ—deep zone.

Table 4. Results of the training process of SOM network with 25 output neurons.

\begin{tabular}{ccccc}
\hline Network & $\begin{array}{c}\text { QE } \\
\text { (Teaching) }\end{array}$ & $\begin{array}{c}\text { QE } \\
\text { (Test) }\end{array}$ & $\begin{array}{c}\text { QE } \\
\text { (Validation) }\end{array}$ & Teaching Algorithm (Epochs) \\
\hline SOFM 196-25 & 0.86 & 1.02 & 0.93 & Kohonen 1000 \\
\hline
\end{tabular}

A sensitivity analysis, performed to verify which wavenumbers contributed most to the classification (grouping) process, revealed that the ratios of the residuals' sum of squares of the full model to its value when the examined variable was removed from the network were equal to or greater than one for 130 variables. The wavenumber ranges determined by the sensitivity analysis are presented in Figure 7 . It shows that the most significant spectral regions for the correctness of the classification include ranges assigned to, among others, amide I (range 1), amide II (range 2) and amide III (range 5), glycosaminoglycans (range 4), $\mathrm{CH}_{2}$ and $\mathrm{CH}_{3}$ vibrations (range 3 ) and absorptions of carbohydrate moieties, including proteoglycans (range 6). Note that the spectra regions indicated in the sensitivity process are similar to those pointed in the analysis of PCA factor loadings, which leads to the conclusion that mentioned ranges are a kind of the fingerprint for the articular cartilage and allow identification of structural variations in the examined zones. 


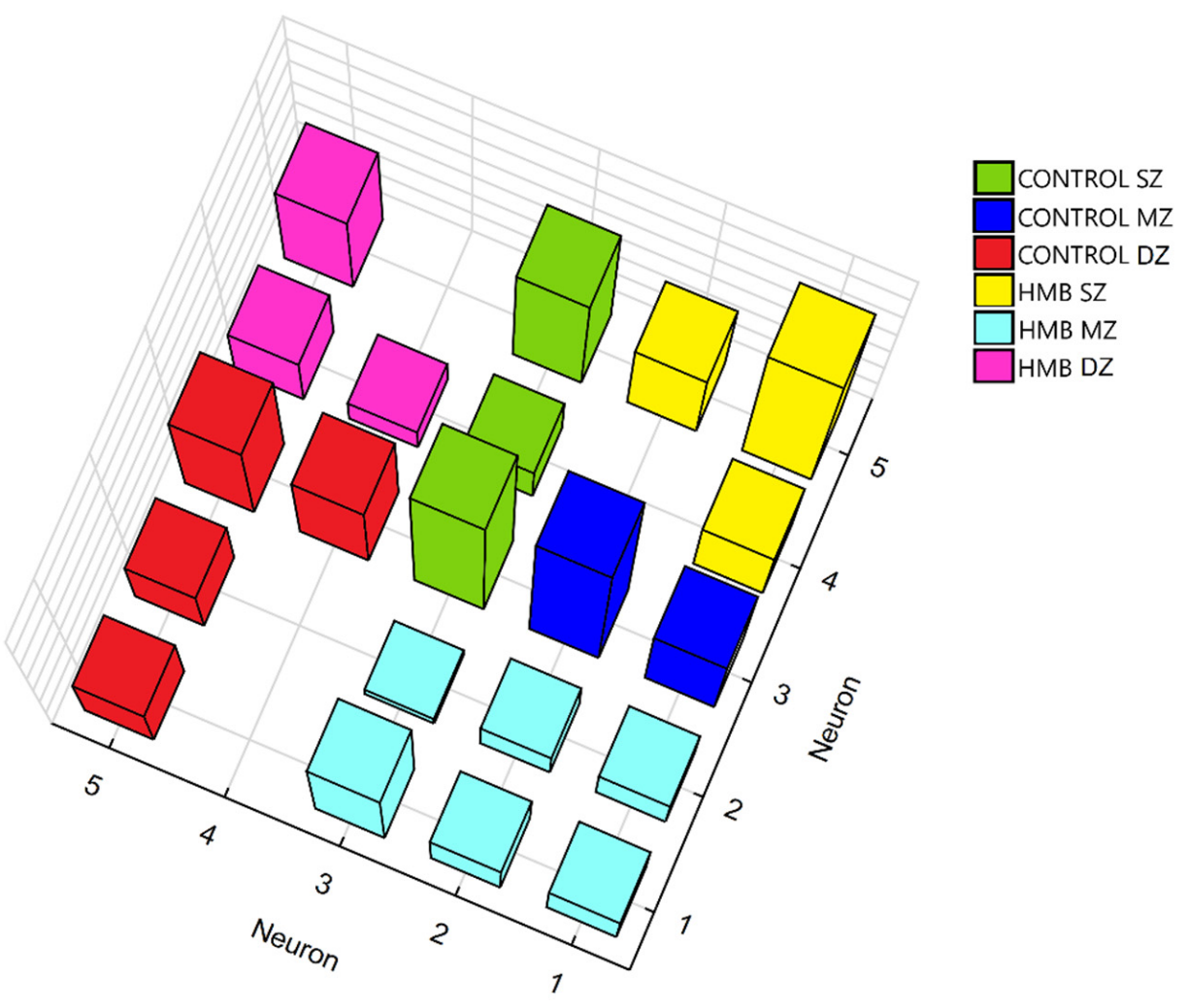

Figure 6. Clusters formed by neurons winning for specified cartilage zones in the control and HMB-supplemented group. HMB—supplemented group, SZ—superficial zone, MZ—middle zone, DZ_deep zone.

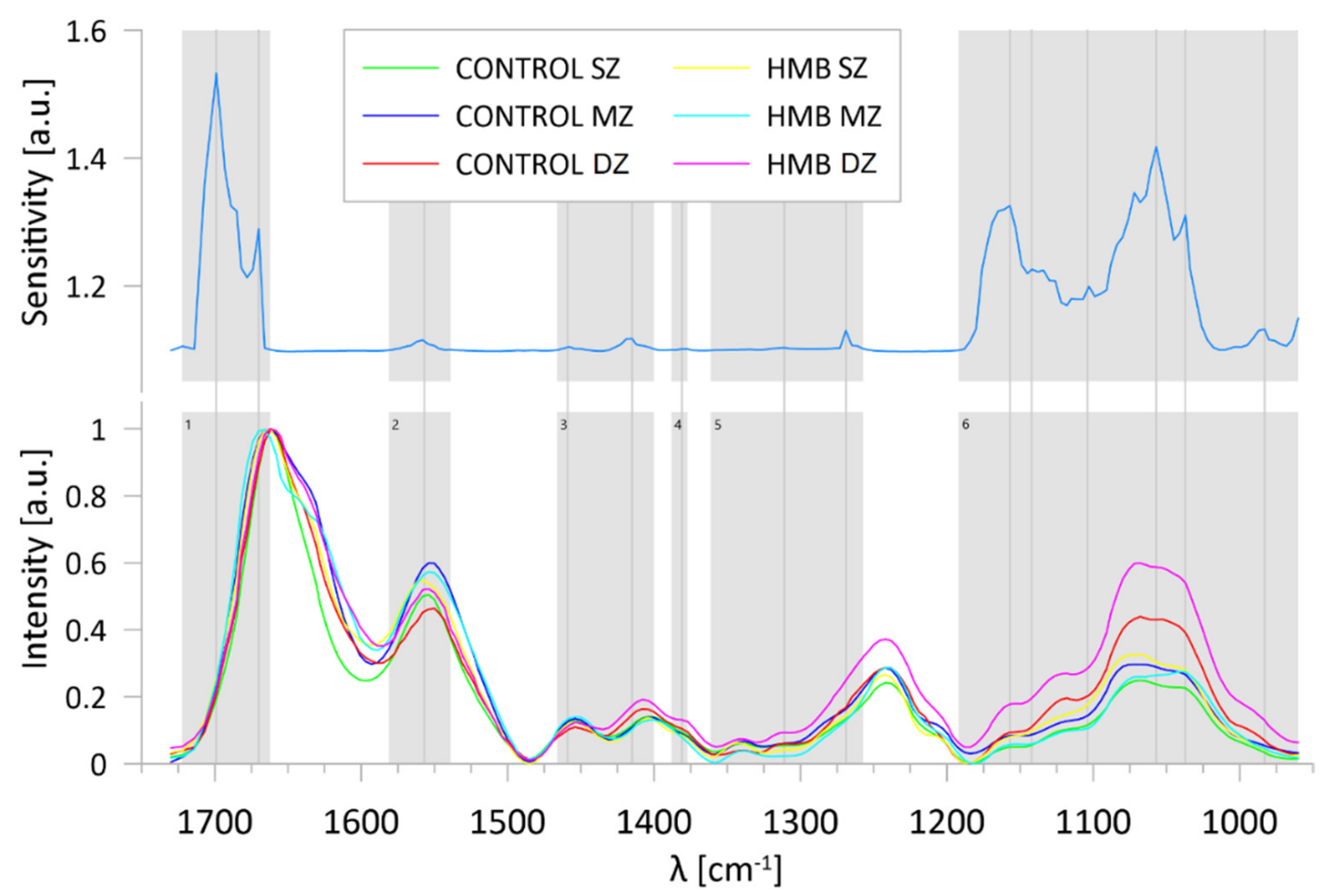

Figure 7. Wavenumber ranges indicated by the ANNs sensitivity analysis with marked peaks in each (grey, vertical lines) and corresponding spectra averaged for each group: (range 1) 1722-1667 cm-1; (range 2) 15981-1539 $\mathrm{cm}^{-1}$; (range 3) 1466-1400 cm-1; (range 4) 1385-1377 cm $\mathrm{cm}^{-1}$; (range 5) 1361-1257 cm SZ-superficial zone, MZ—middle zone, DZ—deep zone. 


\section{Materials and Methods}

Articular cartilage samples were subjected to Fourier Transform Infrared microspectroscopy measurement. Spectra were collected from the three cartilage zones: superficial zone (SZ), middle zone (MZ) and deep zone (DZ). The obtained data were processed, and multidimensional analysis was applied to detect features that allow cartilage zones to be distinguished and alterations in their structure to be recognized. Additionally, AFM measurements were conducted to determine the structure and mechanical properties of the examined regions. The experiment was approved by The Local Ethics Committee for Animal Experimentation of University of Life Sciences in Lublin, Poland (reference number 2014/29) and was carried on following EU Directive 2010/63/EU.

\subsection{Sample Preparation}

Cartilage samples were harvested from 35-day old male piglets of Polish Large White (PLW) breed both from the control $(\mathrm{C}, n=5)$ and experimental group $(\mathrm{HMB}, n=5)$, which were fed a special diet during the fetal period. Pregnant sows received either a basal diet (control group) or the same diet supplemented with $\mathrm{HMB}$ at the dose of $0.2 \mathrm{~g} / \mathrm{kg}$ of body weight/day (HMB group) from 70th until the 90th day of gestation. The gestation length did not differ between the control and HMB sows. All piglets were born by physiological partum, and no congenital changes were detected. The whole experimental set is described in detail in [18] and in [19]. Frozen tissue material was cut on an NX50 cryostat (Thermo Scientific, Waltham, MA, USA) into sections 7-10 $\mu \mathrm{m}$ thick (for FTIR) and $100 \mu \mathrm{m}$ thick (for AFM). A total of 10 samples was obtained ( $n=5$ for the group) for each analysis (the scheme of sample distribution available in Supplementary Material, Figure S6). For FTIR measurements, the samples were mounted on low emissivity (low-e) microscope slides (Kevley Technologies, Chesterland, OH, USA) and subjected to analysis after air-drying for $1 \mathrm{~h}$. In the case of AFM measurements, Superfrost Plus glass slides (Thermo Scientific, Braunschweig, Germany) covered with double-sided adhesive tape were used. Samples were stored at $-20^{\circ} \mathrm{C}$ until investigated.

\subsection{Fourier Transform Infrared Microspectroscopy (FTIR Microspectroscopy) and Data Pre-Processing}

FTIR microspectroscopy measurements were performed using a Hyperion 3000 Vis-IR microscope with a Vertex 70v spectrometer (Bruker Optik GmbH, Ettlingen, Germany) equipped with liquid nitrogen cooled with a $64 \times 64$ focal plane array (FPA) detector using a globar source. For each tissue sample $(n=10)$ seeded on the low-e slide, the IR mapping data were acquired in trans-reflectance mode using a $36 \times$ objective in the spectral range of $4000-750 \mathrm{~cm}^{-1}$ at $4 \mathrm{~cm}^{-1}$ spectral resolution. The samples were imaged to cover a $75 \times 75 \mu \mathrm{m}$ area, achieving a pixel resolution of $1.1 \mu \mathrm{m}$. Thus, for each pixel, the number of scans per spectrum was equal to 64 .

The resulting FTIR spectra fixed in spectral imaging data were extracted and preprocessed using a CytoSpec ${ }^{\mathrm{TM}}$ version 2.00.01 software (Cytospec Inc., Boston, MA, USA). Before further analysis, the poor-quality spectra were removed from the dataset performing the quality test based on checking thickness, signal-to-noise ratio and enough high maximum absorbance in the region $1800-1600 \mathrm{~cm}^{-1}$. A noise-reduction algorithm, a second-order polynomial baseline correction and minimum-maximum normalization of all spectra were applied to optimize the spectral data from all tissue sections. The remaining spectra were cut to include only the fingerprint region between 1730 and $900 \mathrm{~cm}^{-1}$. The background spectra were collected from a pure low-e slide and subtracted automatically using the same acquisition procedure as tissue samples. For each experimental object ( $n=10,5$ for the control and 5 for the experimental group) and from each cartilage zone, five regions of interest (ROI) with dimensions of $10 \times 10$ pixels, with 1 pixel corresponding to $1.19 \times 1.19 \mu^{2}$, were selected. The averaged FTIR spectra from those regions were subjected to further analysis to minimize the error resulting from variations in sample thickness. 


\subsection{Chemical Mapping}

Chemical maps were created by integrating the area under the curve for regions giving quantitative chemical information of the principal macromolecular components of the AC tissue. The integrated area of the amide I absorbance $\left(1750-1590 \mathrm{~cm}^{-1}\right)$ has been used to quantify the collagen content $(\mathrm{CC})$, whereas the integrated area of the region that is assigned to the PG sugar ring (1140-965 $\left.\mathrm{cm}^{-1}\right)$ was correlated with the PGs content (PG) [23]. The ratio of the area of the $\mathrm{CH}_{2}$ side chain of collagen $\left(1360-1325 \mathrm{~cm}^{-1}\right)$ absorption to the amide II (1590-1490 $\left.\mathrm{cm}^{-1}\right)$ was used to determine collagen integrity (CI). All the parameters were collected within previously defined ROIs.

Statistical analysis of calculated parameters was performed using Statistica13.1 (TIBCO Software Inc. Palo Alto, CA, USA) and OriginPro 2016 (OriginLab Co., Northampton, MA, USA). The resulted dataset was checked for the distribution normality by the Shapiro-Wilk test, while the homogeneity of the variance was studied using the Levene test. Normally distributed variables were analyzed using a two-tailed Student's $t$-test or $t$-test with Welch's correction when data lacked equal variances; non-parametric data were analyzed using a Mann-Whitney U test. Data of collagen content, collagen integrity and proteoglycan content were analyzed using the GLM MIXED procedure of SAS (SAS Institute. Inc., Cary, NC, USA) with the dietary treatment as fixed effect and pig as a random effect. Analysis was performed separately for each histological layer of non-calcified articular cartilage to assess differences between the control (C) and supplemented (HMB) group in terms of the parameters characterizing the structure of AC within the studied zones. For all tests, a $p$-value $<0.05$ was established as statistically significant.

\subsection{AFM Nanoindentation}

AFM measurements were taken using a NanoWizard I AFM (JPK Instruments, Berlin, Germany) equipped with an inverse optical microscope (Axiovert 200, Carl Zeiss MicroImaging $\mathrm{GmbH}$, Göttingen, Germany). For the imaging and indentation measurements, silicon nitride cantilevers (MLCT Microcantilever, Bruker, Mannheim, Germany) with a nominal spring constant of $0.1 \mathrm{~N} / \mathrm{m}$ and pyramidal tips with the nominal radius of $20 \mathrm{~nm}$ were used. The actual values of the spring constant were determined using the thermal noise method [76,77] and averaged from the three trials. All the images (in height and vertical deflection domains) were taken with a slow scan rate of $1 \mathrm{~Hz}$ and with a resolution of $512 \times 512$ pixels per image. Additionally, $25 \times 25$ force-indentation curves were recorded for each sample. Measurements were taken for two samples from each examined group and were conducted in a phosphate-buffered saline (PBS) solution. Only extracellular matrix $(\mathrm{ECM})$ was investigated within the analyzed zones, while chondrocytes with surrounding pericellular matrix (PCM) were skipped. Young's modulus was calculated according to a modified Hertz model for a pyramidal indenter (Equation (1)) with the JPK Data Processing software (v.4.2.20, JPK Instruments AG, Berlin, Germany) application. The influence of the substrate was excluded by the reduction of the maximum indentation depth to a few per cent (lower than 10\%) of the sample thickness (force-distant curves were analyzed up to $500 \mathrm{~nm}$ indentation depth).

$$
F=\frac{2 \operatorname{tg} \alpha E}{\pi\left(1-v^{2}\right)} \cdot \delta^{2},
$$

where: $F$-force required to push the tip into the sample, $\delta$-indentation depth, $\alpha$-tip half-opening angle $\left(17.5^{\circ}\right), v$-the Poisson's ratio (0.5 for biological materials $\left.[61,65,78,79]\right)$.

Histograms of the stiffness distributions were calculated separately for each cartilage zone, the maxima of which were located with OriginPro 2016 (OriginLab Co., Northampton, MA, USA) by fitting Gaussian functions or, in the case of the deep zone, a linear combination of them [65]. Statistical differences between peaks' values were checked by the $t$-Student test (Statistica13.1, TIBCO Software Inc. Palo Alto, CA, USA) after verifying that the test conditions were met. 


\subsection{Data Processing}

IR spectra were randomly selected with the CytoSpec ${ }^{\mathrm{TM}}$ from the FTIR images of all ten articular cartilage samples. The 15 representative spectra were extracted from each sample and each region ( $n=45$ per section) within the previously defined ROI. Data were prepared in the form of the matrix $X=\left[x_{i j}\right]_{d \times m}$, the elements of which represented the values of signal intensity (absorbance), lines (d) corresponded to subsequent observations and the variables $(\mathrm{m})$ were the values of wave numbers expressed in $\mathrm{cm}^{-1}$. Since the sampling rate was equal to about $4 \mathrm{~cm}^{-1}\left(3.93 \mathrm{~cm}^{-1}\right), 196$ variables were obtained in the tested range. Consequently, the final spectral data set, containing 450 spectra in the spectral region of $1730-960 \mathrm{~cm}^{-1}$, was subjected to further analysis with PCA and ANNs application.

\subsection{Principal Component Analysis (PCA)}

The principal component analysis (PCA) was performed (Statistica13.1, TIBCO Software Inc. Palo Alto, CA, USA) to reduce the number of variables (FTIR spectral vectors) into a few principal components (PCs). PC scores were achieved from data sets on correlation mode, and the variance was plotted on a 2D axis. The scree plots and the Kaiser-Guttmann criterion were used to select an optimum number of variables. The data matrix was scaled to the unitary standard deviation, which means that PCA was done on the correlation matrix, and all the variables were treated on an equal footing.

\subsection{Artificial Neural Networks (ANNs)}

The input for artificial neural networks was a set of four hundred and fifty 196-element vectors, the standardized components of which reflected the absorbance intensities depending on the value of the wavenumber. In addition, the data matrix was randomly divided into training, test and validation sets in the ratio of 75:15:15 and used as an input for classifying and grouping networks.

MLP network, chosen to classify spectra into one of six groups, had one hidden layer with 18 neurons activated with logistic function and 6 outputs activated by the softmax function. The architecture of the classifying network was determined using the growth method. The MLP network was trained with the Broyden-Fletcher-GoldfarbShanno (BFGS) algorithm [73] for 100 epochs, with a constant learning coefficient of 0.01 and momentum of 0.80 . The acceptance and rejection thresholds were 0.95 and 0.05 , respectively, corresponding to the standard classification at the $95 \%$ confidence level. As an error function, cross-entropy (CE) was applied (Equation (2)) due to the fact that CE implementation allows interpreting output values as the probabilities of the object group membership [80].

$$
E_{C E}=-\sum_{i=1}^{N} y_{i}\left(\frac{d_{i}}{y_{i}}\right),
$$

where: $y_{i}$-real output value, $d_{i}$ —expected output value, $N$ —the number of teaching pairs input-output.

Kohonen network (Self Organising Map, SOM), which aimed to group the spectra according to their similarity, was built with 25 output neurons. As an error function, quantization error (QE, Equation (3)) was used. QE measures the distance of the winning neuron weight vector from the input vector, i.e., the distance of the input pattern from the nearest center, which expresses the accuracy of mapping the input data by the winning neuron [75]. Since QE allows assessing the neuron map fitting to the input data, the network with the lowest error value was chosen.

$$
Q E=\frac{1}{Q} \sum_{q=1}^{T Q}\|x-w\|,
$$

where: $x$-the input vector; $w$-the weight vector of the winning neuron for the $x$ vector. 
SOM network was trained with 1000 epochs according to Kohonen WTM (winner takes most) rule (Equation (4)) [75], with decreasing learning rate (0.9-0.01) and neighborhood (from 5 to 0 ).

$$
w_{i j}(t+1)=w_{i j}(t)+\alpha(t) h_{c i}(t)\left[x_{j}-w_{i j}(t)\right]
$$

where: $w_{i j}(t+1)$ - the element of the weight vector of the connection between the $i$-th neuron and the $j$-th input vector in the current learning cycle; $w_{i j}(t)$ - the element of the weight vector of the connection between the $i$-th neuron and the $j$-th input vector in the previous learning cycle; $0<\alpha(t)<1$-decreasing learning rate, $h_{c i}(t)$-the neighborhood function decreasing in time with respect to the winning neuron, $t$ - previous teaching cycle, $t+1$-current teaching cycle.

For all the variables, sensitivity analysis was performed to determine the ranges that are crucial for classification. All the simulations were conducted in Statistica13.1 software (TIBCO Software Inc. Palo Alto, CA, USA).

\section{Conclusions}

To sum up, this is the first report combining FTIR imaging with multivariate analysis to study the effect of the HMB supplementation on the structure and properties of articular cartilage. Experimental results confirm that Fourier transform infrared microspectroscopy imaging has potential as a quantitative alternative to conventional methods such as histology and biochemical analysis to characterize the articular cartilage components. Moreover, it gives the possibility to obtain novel biochemical information from investigated samples in a non-destructive and no staining required fashion. Quantitative FTIR mapping has revealed both zonal- and experimental group-dependent changes within the AC tissue after the HMB treatment, which was reflected in mechanical features of cartilage proved by AFM measurements. The relatively higher amount of collagen content was localized in the superficial and the middle zone. At the same time, the distribution of proteoglycans significantly increased in the middle and deep zones compared to the untreated HMB group. These findings were consistent with our previous works utilizing traditional biochemical assays.

Furthermore, the application of the multivariate analysis to the spectral data revealed the existence of frequency ranges that allow for an unambiguous classification of the spectrum, which in the case of a heterogeneous tissue in which the boundary between individual zones is often challenging to define, may constitute the basis for creating a supporting method for this type of investigation. Finally, it should be underlined that only a few studies have applied machine learning techniques based on artificial neural networks for the analysis and processing of cartilage MIR spectral data [58]. Nevertheless, ANNs were considered a promising tool in this type of analysis. Moreover, since their potential implications for the cartilage condition diagnosis and monitoring were highlighted, it may imply direction for further research.

Supplementary Materials: The following are available online at https:/ /www.mdpi.com/article/10 $.3390 / \mathrm{ijms} 22179189 / \mathrm{s} 1$.

Author Contributions: Conceptualization, I.Ś., E.T. and M.A.; Data curation, I.Ś. and M.A.; Formal analysis, I.Ś., M.Ś. and M.A.; Investigation, I.Ś., S.M., C.P., M.Ś., K.K. and M.A.; Methodology, I.Ś., S.M., C.P., H.C.-S., A.A., M.B.A. and M.A.; Project administration, I.Ś.; Resources, H.C.-S., A.A., M.B.A., M.G. and P.D.; Supervision, E.T. and M.A.; Validation, I.Ś. and T.B.; Visualization, I.Ś., S.M., M.Ś. and M.A.; Writing—original draft, I.Ś. and M.A.; Writing—review and editing, S.M., A.A. and M.A. All authors have read and agreed to the published version of the manuscript.

Funding: This research received no external funding.

Institutional Review Board Statement: The experiment was approved by The Local Ethics Committee for Animal Experimentation of University of Life Sciences in Lublin, Poland (reference number 2014/29) and was carried on following EU Directive 2010/63/EU.

Informed Consent Statement: Not applicable. 
Data Availability Statement: Data reported in this manuscript will be available upon request.

Conflicts of Interest: The authors declare no conflict of interest.

\section{References}

1. Mauck, R.L.; Soltz, M.A.; Wang, C.C.; Wong, D.D.; Chao, P.H.; Valhmu, W.B.; Hung, C.T.; Ateshian, G.A. Functional tissue engineering of articular cartilage through dynamic loading of chondrocyte-seeded agarose gels. J. Biomech. Eng. 2000, 122, 252-260. [CrossRef] [PubMed]

2. Kinnunen, J.; Saarakkala, S.; Hauta-Kasari, M.; Vahimaa, P.; Jurvelin, J.S. Optical spectral reflectance of human articular cartilageRelationships with tissue structure, composition and mechanical properties. Biomed. Opt. Express 2011, 2, 1394-1402. [CrossRef] [PubMed]

3. Huber, M.; Trattnig, S.; Lintner, F. Anatomy, biochemistry, and physiology of articular cartilage. Investig. Radiol. 2000, 35, 573-580. [CrossRef]

4. Ramakrishnan, N.; Xia, Y.; Bidthanapally, A.; Lu, M. Determination of zonal boundaries in articular cartilage using infrared dichroism. Appl. Spectrosc. 2007, 61, 1404-1409. [CrossRef] [PubMed]

5. Oinas, J.; Ronkainen, A.P.; Rieppo, L.; Finnilä, M.A.J.; Iivarinen, J.T.; van Weeren, P.R.; Helminen, H.J.; Brama, P.A.J.; Korhonen R.K.; Saarakkala, S. Composition, structure and tensile biomechanical properties of equine articular cartilage during growth and maturation. Sci. Rep. 2018, 8, 11357. [CrossRef] [PubMed]

6. Bayliss, M.T.; Venn, M.; Maroudas, A.; Ali, S.Y. Structure of proteoglycans from different layers of human articular cartilage. Biochem. J. 1983, 209, 387-400. [CrossRef] [PubMed]

7. Mow, V.C.; Ratcliffe, A.; Poole, A.R. Cartilage and diarthrodial joints as paradigms for hierarchical materials and structures. Biomaterials 1992, 13, 67-97. [CrossRef]

8. van Turnhout, M.C.; Schipper, H.; Engel, B.; Buist, W.; Kranenbarg, S.; van Leeuwen, J.L. Postnatal development of collagen structure in ovine articular cartilage. BMC Dev. Biol. 2010, 10, 62. [CrossRef] [PubMed]

9. Hayes, A.J.; Melrose, J. Aggrecan, the Primary Weight-Bearing Cartilage Proteoglycan, Has Context-Dependent, Cell-Directive Properties in Embryonic Development and Neurogenesis: Aggrecan Glycan Side Chain Modifications Convey Interactive Biodiversity. Biomolecules 2020, 10, 1244. [CrossRef]

10. Fox, A.J.S.; Bedi, A.; Rodeo, S.A. The Basic Science of Articular Cartilage: Structure, Composition, and Function. Sports Health 2009, 1, 461-468. [CrossRef]

11. Huey, D.J.; Hu, J.C.; Athanasiou, K.A. Unlike Bone, Cartilage Regeneration Remains Elusive. Science 2012, 338, 917-921. [CrossRef]

12. Slater, G.J.; Jenkins, D. Beta-hydroxy-beta-methylbutyrate (HMB) supplementation and the promotion of muscle growth and strength. Sports Med. (Auckl. N.Z.) 2000, 30, 105-116. [CrossRef]

13. Kovarik, M.; Muthny, T.; Sispera, L.; Holecek, M. Effects of $\beta$-hydroxy- $\beta$-methylbutyrate treatment in different types of skeletal muscle of intact and septic rats. J. Physiol. Biochem. 2010, 66, 311-319. [CrossRef]

14. Holeček, M. Beta-hydroxy-beta-methylbutyrate supplementation and skeletal muscle in healthy and muscle-wasting conditions. J. Cachexia Sarcopenia Muscle 2017, 8, 529-541. [CrossRef] [PubMed]

15. Hao, Y.; Jackson, J.R.; Wang, Y.; Edens, N.; Pereira, S.L.; Alway, S.E. $\beta$-Hydroxy- $\beta$-methylbutyrate reduces myonuclear apoptosis during recovery from hind limb suspension-induced muscle fiber atrophy in aged rats. Am. J. Physiol.-Regul. Integr. Comp. Physiol. 2011, 301, R701-R715. [CrossRef] [PubMed]

16. Engelen, M.P.K.J.; Deutz, N.E.P. Is $\beta$-hydroxy $\beta$-methylbutyrate an effective anabolic agent to improve outcome in older diseased populations? Curr. Opin. Clin. Nutr. Metab. Care 2018, 21, 207-213. [CrossRef] [PubMed]

17. Santos-Fandila, A.; Zafra-Gómez, A.; Barranco, A.; Navalón, A.; Rueda, R.; Ramírez, M. Quantitative determination of $\beta$ hydroxymethylbutyrate and leucine in culture media and microdialysates from rat brain by UHPLC-tandem mass spectrometry. Anal. Bioanal. Chem. 2014, 406, 2863-2872. [CrossRef] [PubMed]

18. Blicharski, T.; Tomaszewska, E.; Dobrowolski, P.; Hułas-Stasiak, M.; Muszyński, S. A metabolite of leucine ( $\beta$-hydroxy- $\beta$ methylbutyrate) given to sows during pregnancy alters bone development of their newborn offspring by hormonal modulation. PLoS ONE 2017, 12, e0179693. [CrossRef]

19. Tomaszewska, E.; Muszyński, S.; Dobrowolski, P.; Wiącek, D.; Tomczyk-Warunek, A.; Świetlicka, I.; Pierzynowski, S.G. Maternal HMB treatment affects bone and hyaline cartilage development in their weaned piglets via the leptin/osteoprotegerin system. J. Anim. Physiol. Anim. Nutr. 2019, 103, 626-643. [CrossRef]

20. Szcześniak, K.A.; Ostaszewski, P.; Fuller, J.C.; Ciecierska, A.; Sadkowski, T. Dietary supplementation of $\beta$-hydroxy- $\beta$ methylbutyrate in animals-A review. J. Anim. Physiol. Anim. Nutr. 2015, 99, 405-417. [CrossRef]

21. Tomczyk-Warunek, A.; Blicharski, T.; Jarecki, J.; Dobrowolski, P.; Muszyński, S.; Tomaszewska, E.; Rovati, L.C. The effect of maternal HMB supplementation on bone mechanical and geometrical properties, as well as histomorphometry and immunolocalization of VEGF, TIMP2, MMP13, BMP2 in the bone and cartilage tissue of the humerus of their newborn piglets. PLoS ONE 2021, 16, e0240642. [CrossRef] [PubMed]

22. Boskey, A.; Pleshko Camacho, N. FT-IR imaging of native and tissue-engineered bone and cartilage. Biomaterials 2007, 28, 2465-2478. [CrossRef]

23. Camacho, N.P.; West, P.; Torzilli, P.A.; Mendelsohn, R. FTIR microscopic imaging of collagen and proteoglycan in bovine cartilage. Biopolymers 2001, 62, 1-8. [CrossRef] 
24. Potter, K.; Kidder, L.H.; Levin, I.W.; Lewis, E.N.; Spencer, R.G.S. Imaging of collagen and proteoglycan in cartilage sections using Fourier transform infrared spectral imaging. Arthritis Rheum. 2001, 44, 846-855. [CrossRef]

25. Rieppo, J.; Hyttinen, M.M.; Halmesmaki, E.; Ruotsalainen, H.; Vasara, A.; Kiviranta, I.; Jurvelin, J.S.; Helminen, H.J. Changes in spatial collagen content and collagen network architecture in porcine articular cartilage during growth and maturation. Osteoarthr. Cartil. 2009, 17, 448-455. [CrossRef] [PubMed]

26. Rieppo, L.; Saarakkala, S.; Närhi, T.; Holopainen, J.; Lammi, M.; Helminen, H.J.; Jurvelin, J.S.; Rieppo, J. Quantitative analysis of spatial proteoglycan content in articular cartilage with Fourier transform infrared imaging spectroscopy: Critical evaluation of analysis methods and specificity of the parameters. Microsc. Res. Tech. 2010, 73, 503-512. [CrossRef]

27. Yu, C.; Zhao, B.; Li, Y.; Zang, H.; Li, L. Vibrational Spectroscopy in Assessment of Early Osteoarthritis-A Narrative Review. Int. J. Mol. Sci. 2021, 22, 5235. [CrossRef]

28. West, P.A.; Bostrom, M.P.; Torzilli, P.A.; Camacho, N.P. Fourier transform infrared spectral analysis of degenerative cartilage: An infrared fiber optic probe and imaging study. Appl. Spectrosc. 2004, 58, 376-381. [CrossRef]

29. Rieppo, L.; Saarakkala, S.; Närhi, T.; Helminen, H.J.; Jurvelin, J.S.; Rieppo, J. Application of second derivative spectroscopy for increasing molecular specificity of Fourier transform infrared spectroscopic imaging of articular cartilage. Osteoarthr. Cartil. 2012, 20, 451-459. [CrossRef]

30. Mao, Z.-H.; Wu, Y.-C.; Zhang, X.-X.; Gao, H.; Yin, J.-H. Comparative study on identification of healthy and osteoarthritic articular cartilages by fourier transform infrared imaging and chemometrics methods. J. Innov. Opt. Health Sci. 2017, 10, 1650054 [CrossRef]

31. Oinas, J.; Rieppo, L.; Finnilä, M.A.J.; Valkealahti, M.; Lehenkari, P.; Saarakkala, S. Imaging of Osteoarthritic Human Articular Cartilage using Fourier Transform Infrared Microspectroscopy Combined with Multivariate and Univariate Analysis. Sci. Rep. 2016, 6, 30008. [CrossRef] [PubMed]

32. Yin, J.; Xia, Y.; Xiao, Z. Comparison of macromolecular component distributions in osteoarthritic and healthy cartilages by Fourier Transform Infrared imaging. J. Innov. Opt. Health Sci. 2013, 06, 1350048. [CrossRef]

33. Bi, X.; Yang, X.; Bostrom, M.P.G.; Camacho, N.P. Fourier transform infrared imaging spectroscopy investigations in the pathogenesis and repair of cartilage. Biochim. Biophys. Acta (BBA) Biomembr. 2006, 1758, 934-941. [CrossRef]

34. Kobrina, Y.; Rieppo, L.; Saarakkala, S.; Pulkkinen, H.J.; Tiitu, V.; Valonen, P.; Kiviranta, I.; Jurvelin, J.S.; Isaksson, H. Cluster analysis of infrared spectra can differentiate intact and repaired articular cartilage. Osteoarthr. Cartil. 2013, 21, 462-469. [CrossRef]

35. Gutierrez, K.; Dicks, N.; Glanzner, W.; Agellon, L.; Bordignon, V. Efficacy of the porcine species in biomedical research. Front. Genet. 2015, 6, 293. [CrossRef]

36. Humphray, S.J.; Scott, C.E.; Clark, R.; Marron, B.; Bender, C.; Camm, N.; Davis, J.; Jenks, A.; Noon, A.; Patel, M.; et al. A high utility integrated map of the pig genome. Genome Biol. 2007, 8, R139. [CrossRef] [PubMed]

37. Williams, G.M.; Klisch, S.M.; Sah, R.L. Bioengineering Cartilage Growth, Maturation, and Form. Pediatric Res. 2008, 63, 527-534. [CrossRef]

38. Tatara, M.R.; Śliwa, E.; Krupski, W. Prenatal programming of skeletal development in the offspring: Effects of maternal treatment with $\beta$-hydroxy $\beta$-methylbutyrate (HMB) on femur properties in pigs at slaughter age. Bone 2007, 40, 1615-1622. [CrossRef]

39. Flummer, C.; Kristensen, N.B.; Theil, P.K. Body composition of piglets from sows fed with the leucine metabolite $\beta$-hydroxy $\beta$-methylbutyrate in late gestation. J. Anim. Sci. 2012, 90, 442-444. [CrossRef]

40. Tomaszewska, E.; Dobrowolski, P.; Kostro, K.; Jakubczak, A.; Taszkun, I.; Jaworska-Adamu, J.; Żmuda, A.; Rycerz, K.; Muszyński, $\mathrm{S}$. Effect of HMB and 2-Ox administered during pregnancy on bone properties in primiparous and multiparous minks (Neivison vison). Bull. Vet. Inst. Pulawy 2015, 59, 563-568. [CrossRef]

41. Świetlicka, I.; Muszyński, S.; Tomaszewska, E.; Dobrowolski, P.; Kwaśniewska, A.; Świetlicki, M.; Skic, A.; Gołacki, K. Prenatally administered HMB modifies the enamel surface roughness in spiny mice offspring: An Atomic Force Microscopy study. Arch. Oral Biol. 2016, 70, 24-31. [CrossRef] [PubMed]

42. Tomaszewska, E.; Dobrowolski, P.; Świetlicka, I.; Muszyński, S.; Kostro, K.; Jakubczak, A.; Taszkun, I.; Żmuda, A.; Rycerz, K.; Blicharski, T.; et al. Effects of maternal treatment with $\beta$-hydroxy- $\beta$-metylbutyrate and 2-oxoglutaric acid on femur development in offspring of minks of the standard dark brown type. J. Anim. Physiol. Anim. Nutr. 2018, 102, 299-308. [CrossRef] [PubMed]

43. Eley, H.L.; Russel, S.T.; Baxter, J.H.; Mukerji, P.; Tisdale, M.J. Signaling pathways initiated by b-hydroxy-bmethylbutyrate to attenuate the depression of protein synthesis in skeletal muscle in response to cachectic stimuli. Am. J. Physiol. Endocrinol. Metab. 2007, 293, 923-931. [CrossRef]

44. Eley, H.L.; Russel, S.T.; Tisdale, M.J. Mechanism of attenuation of depression of muscle protein degradation induced by tumor necrosis factor-a and angiotensin II by b-hydroxy-bmethylbutyrate. Am. J. Physiol. Endocrinol. Metab. 2008, 295, 1417-1426. [CrossRef] [PubMed]

45. Holecek, M.; Muthny, T.; Kovarlik, M.; Sispera, L. Effect of betahydroxy-beta-methylbutyrate (HMB) on protein metabolism in whole body and in selected tissues. Food Chem. Toxicol. 2009, 47, 255-259. [CrossRef]

46. Aversa, Z.; Bonetto, A.; Costelli, P.; Minero, V.G.; Penna, F.; Baccino, F.M.; Lucia, S.; Fanelli, F.R.; Muscaritoli, M. $\beta$-hydroxy- $\beta$ methylbutyrate (HMB) attenuates muscle and body weight loss in experimental cancer cachexia. Int. J. Oncol. 2011, 38, 713-720. [PubMed] 
47. Wilkinson, D.J.; Hossain, T.; Hill, D.S.; Phillips, B.E.; Crossland, H.; Williams, J.; Loughna, P.; Churchward-Venne, T.A.; Breen, L.; Phillips, S.M.; et al. Effects of leucine and its metabolite betahydroxy-beta-methylbutyrate on human skeletal muscle protein metabolism. J. Physiol. 2013, 591, 2911-2923. [CrossRef]

48. Mao, Z.-H.; Yin, J.-H.; Zhang, X.-X.; Wang, X.; Xia, Y. Discrimination of healthy and osteoarthritic articular cartilage by Fourier transform infrared imaging and Fishers discriminant analysis. Biomed. Opt. Express 2016, 7, 448-453. [CrossRef]

49. Yin, J.; Xia, Y.; Lu, M. Concentration profiles of collagen and proteoglycan in articular cartilage by Fourier transform infrared imaging and principal component regression. Spectrochim. Acta Part A Mol. Biomol. Spectrosc. 2012, 88, 90-96. [CrossRef]

50. Kong, J.; Yu, S. Fourier transform infrared spectroscopic analysis of protein secondary structures. Acta Biochim. Biophys. Sin. 2007, 39, 549-559. [CrossRef]

51. Susi, H.; Byler, D.M. Resolution-enhanced fourier transform infrared spectroscopy of enzymes. In Methods in Enzymology; Academic Press: Cambridge, MA, USA, 1986; Volume 130, pp. 290-311.

52. de Campos Vidal, B.; Mello, M.L.S. Collagen type I amide I band infrared spectroscopy. Micron 2011, 42, 283-289. [CrossRef] [PubMed]

53. Croxford, A.M.; Crombie, D.; McNaughton, D.; Holmdahl, R.; Nandakumar, K.S.; Rowley, M.J. Specific antibody protection of the extracellular cartilage matrix against collagen antibody-induced damage. Arthritis Rheum. 2010, 62, 3374-3384. [CrossRef]

54. Shah, N.B.; Wolkers, W.F.; Morrissey, M.; Sun, W.Q.; Bischof, J.C. Fourier Transform Infrared Spectroscopy Investigation of Native Tissue Matrix Modifications Using a Gamma Irradiation Process. Tissue Eng. Part C Methods 2008, 15, 33-40. [CrossRef] [PubMed]

55. Xu, J.; Zhu, P.; Morris, M.D.; Ramamoorthy, A. Solid-State NMR Spectroscopy Provides Atomic-Level Insights Into the Dehydration of Cartilage. J. Phys. Chem. B 2011, 115, 9948-9954. [CrossRef]

56. Kemp, A.D.; Harding, C.C.; Cabral, W.A.; Marini, J.C.; Wallace, J.M. Effects of tissue hydration on nanoscale structural morphology and mechanics of individual Type I collagen fibrils in the Brtl mouse model of Osteogenesis Imperfecta. J. Struct. Biol. 2012, 180, 428-438. [CrossRef]

57. Rieppo, L.; Töyräs, J.; Saarakkala, S. Vibrational spectroscopy of articular cartilage. Appl. Spectrosc. Rev. 2017, 52, 249-266. [CrossRef]

58. Linka, K.; Thüring, J.; Rieppo, L.; Aydin, R.C.; Cyron, C.J.; Kuhl, C.; Merhof, D.; Truhn, D.; Nebelung, S. Machine learningaugmented and microspectroscopy-informed multiparametric MRI for the non-invasive prediction of articular cartilage composition. Osteoarthr. Cartil. 2021, 29, 592-602. [CrossRef] [PubMed]

59. Jackson, M.; Mantsch, H.H. The use and misuse of FTIR spectroscopy in the determination of protein structure. Crit. Rev. Biochem. Mol. Biol. 1995, 30, 95-120. [CrossRef]

60. Pogoda, K.; Pięta, E.; Roman, M.; Piergies, N.; Liberda, D.; Wróbel, T.P.; Janmey, P.A.; Paluszkiewicz, C.; Kwiatek, W.M. In search of the correlation between nanomechanical and biomolecular properties of prostate cancer cells with different metastatic potential. Arch. Biochem. Biophys. 2021, 697, 108718. [CrossRef]

61. Prein, C.; Warmbold, N.; Farkas, Z.; Schieker, M.; Aszodi, A.; Clausen-Schaumann, H. Structural and mechanical properties of the proliferative zone of the developing murine growth plate cartilage assessed by atomic force microscopy. Matrix Biol. J. Int. Soc. Matrix Biol. 2016, 50, 1-15. [CrossRef]

62. Danalache, M.; Jacobi, L.F.; Schwitalle, M.; Hofmann, U.K. Assessment of biomechanical properties of the extracellular and pericellular matrix and their interconnection throughout the course of osteoarthritis. J. Biomech. 2019, 97, 109409. [CrossRef] [PubMed]

63. Li, P.; Fleischhauer, L.; Nicolae, C.; Prein, C.; Farkas, Z.; Saller, M.M.; Prall, W.C.; Wagener, R.; Heilig, J.; Niehoff, A.; et al. Mice Lacking the Matrilin Family of Extracellular Matrix Proteins Develop Mild Skeletal Abnormalities and Are Susceptible to Age-Associated Osteoarthritis. Int. J. Mol. Sci. 2020, 21, 666. [CrossRef]

64. Hartmann, B.; Marchi, G.; Alberton, P.; Farkas, Z.; Aszodi, A.; Roths, J.; Clausen-Schaumann, H. Early Detection of Cartilage Degeneration: A Comparison of Histology, Fiber Bragg Grating-Based Micro-Indentation, and Atomic Force Microscopy-Based Nano-Indentation. Int. J. Mol. Sci. 2020, 21, 7384. [CrossRef] [PubMed]

65. Loparic, M.; Wirz, D.; Daniels, A.U.; Raiteri, R.; Vanlandingham, M.R.; Guex, G.; Martin, I.; Aebi, U.; Stolz, M. Micro- and nanomechanical analysis of articular cartilage by indentation-type atomic force microscopy: Validation with a gel-microfiber composite. Biophys. J. 2010, 98, 2731-2740. [CrossRef] [PubMed]

66. Saadat, E.; Lan, H.; Majumdar, S.; Rempel, D.M.; King, K.B. Long-term cyclical in vivoloading increases cartilage proteoglycan content in a spatially specific manner: An infrared microspectroscopic imaging and polarized light microscopy study. Arthritis Res. Ther. 2006, 8, R147. [CrossRef]

67. Ramakrishnan, N.; Xia, Y. Fourier-transform infrared spectroscopic imaging of articular cartilage and biomaterials: A review. Trends Appl. Spectrosc. 2013, 10, 1-23.

68. Jolliffe, I.T. Principal Component Analysis; Springer: New York, NY, USA, 2002.

69. Wang, X.Z.; Yang, Y.; Li, R.; Mcguinnes, C.; Adamson, J.; Megson, I.L.; Donaldson, K. Principal component and causal analysis of structural and acute in vitro toxicity data for nanoparticles. Nanotoxicology 2014, 8, 465-476. [CrossRef]

70. Yao, F.; Coquery, J.; Lê Cao, K.-A. Independent Principal Component Analysis for biologically meaningful dimension reduction of large biological data sets. BMC Bioinform. 2012, 13, 1-15. [CrossRef]

71. Kinkiri, S.; Melis, W.J.C. Reducing data storage requirements for machine learning algorithms using principle component analysis. In Proceedings of the International Conference on Applied System Innovation (ICASI), Okinawa, Japan, 26-30 May 2016. 
72. Mow, V.C.; Guo, X.E. Mechano-electrochemical properties of articular cartilage: Their inhomogeneities and anisotropies. Annu. Rev. Biomed. Eng. 2002, 4, 175-209. [CrossRef]

73. Bishop, C.M. Neural Networks for Pattern Recognition; Oxford University Press: Oxford, UK, 1995.

74. Hassoun, M.H. Fundamentals of Artificial Neural Networks; MIT Press: Cambridge, MA, USA, 1995.

75. Kohonen, T. Self-Organizing Maps; Springer: Berlin, Germany, 2001.

76. Friedrichs, J.; Legate, K.R.; Schubert, R.; Bharadwaj, M.; Werner, C.; Müller, D.J.; Benoit, M. A practical guide to quantify cell adhesion using single-cell force spectroscopy. Methods (San Diego Calif.) 2013, 60, 169-178. [CrossRef]

77. Butt, H.J.; Jaschke, M. Calculation of thermal noise in atomic force microscopy. Nanotechnology 1995, 6, 1-7. [CrossRef]

78. Muschter, D.; Fleischhauer, L.; Taheri, S.; Schilling, A.F.; Clausen-Schaumann, H.; Grässel, S. Sensory neuropeptides are required for bone and cartilage homeostasis in a murine destabilization-induced osteoarthritis model. Bone 2020, 133, 115181. [CrossRef]

79. Reuten, R.; Zendehroud, S.; Nicolau, M.; Fleischhauer, L.; Laitala, A.; Kiderlen, S.; Nikodemus, D.; Wullkopf, L.; Nielsen, S.R.; McNeilly, S.; et al. Basement membrane stiffness determines metastases formation. Nat. Mater. 2021, 20, 892-903. [CrossRef] [PubMed]

80. Zhou, Y.; Wang, X.; Zhang, M.; Zhu, J.; Zheng, R.; Wu, Q. MPCE: A Maximum Probability Based Cross Entropy Loss Function for Neural Network Classification. IEEE Access 2019, 7, 146331-146341. [CrossRef] 